\title{
Bioequivalence of Two Oral Formulations of Modafinil Tablets in Healthy Male Subjects under Fed and Fasting Conditions
}

\author{
AISayed Sallam ${ }^{1}$, Isam I. Salem ${ }^{2}$, Dalia AIJohari ${ }^{3}$, Mohannad Shawer ${ }^{4}$, Bilal Abu Alaasal ${ }^{4}$ and Derar Omari ${ }^{5 *}$ \\ ${ }^{1}$ STD, The Specialized Pharmaceutical Research Co., Amman, Jordan (present address at Al-Taqaddom Pharmaceutical Industries co. Amman, Jordan) \\ ${ }^{2}$ IPRC International Pharmaceutical Research Center (IPRC), Amman, Jordan \\ ${ }^{3}$ Hikma Pharmaceuticals PLC, Amman, Jordan \\ ${ }^{4}$ STD The specialized Pharmaceutical Research Co., Amman, Jordan, (present address: Bosch and Lomb Co., Rochester, NY, USA) \\ ${ }^{5}$ STD, The specialized Pharmaceutical Research Co., Amman, Jordan, (present address: College of Pharmacy, Yarmouk University, Irbid, Jordan)
}

\begin{abstract}
Modafinil is a novel wake-promoting agent for oral administration. The aim of this study was to determine bioequivalence of two tablet formulations: Hikma Modafinil $200 \mathrm{mg}$ tablets relative to the originator Provigil $200 \mathrm{mg}$ tablets after oral administration to healthy subjects under both fed and fasting conditions. Twenty eight subjects, in either fed and fast studies, were enrolled and completed the crossover. The method was designed as open-label, randomized two-way crossover study with a 7-day washout period for each study. Pharmacokinetic parameters of modafinil were estimated using standard non-compartmental methods. The $C_{m a x}, T_{m a x}, A U C_{0-t}$ and $A U C_{0-\infty}$ were calculated. The results of this bioequivalence study showed the equivalence of the two studied products in terms of the rate of absorption as indicated by $\mathrm{C}_{\max }$ and in terms of the extent of absorption as indicated by $\mathrm{AUC}_{0 . \mathrm{t}}$ and $A \cup \mathrm{C}_{0}$ . The parametric $90 \%$ confidence intervals of the mean values for the Test/Reference ratio were in each case well within the bioequivalence acceptable boundaries of $80.00-125.00 \%$ for the pharmacokinetic parameters AUC $A \cup C_{0-\infty}$ and $C_{\max }$. The effect of food is obvious where the $C_{\max }$ and $A U C$ are lower in the fed study compared with fasting.
\end{abstract}

Keywords: Modafinil; Bioequivalence; Pharmacokinetic parameters; Randomized two-way crossover study

\section{Introduction}

Modafinil (d,l-2-[(diphenylmethyl)sulfinyl] acetamide; Figure 1) is a novel wake-promoting agent for oral administration. It is a white to off-white crystalline solid that is practically insoluble in water and cyclohexane and slightly soluble in methanol and acetone. The molecular formula is $\mathrm{C}_{15} \mathrm{H}_{15} \mathrm{NO}_{2} \mathrm{~S}$ and the molecular weight is $273.4 \mathrm{D}$ [1]. Modafinil is a racemate, with a single chiral centre at the sulphur of the sulfoxide. The two enantiomers of modafinil are approximately equipotent in their pharmacological effects in mice. However, the enantiomers are pharmacokinetically dissimilar, although to differing degrees, in all species tested, including humans $[2,3]$.

Due to its solubility characteristics, an intravenous form of the drug is not available and the absolute bioavailability of modafinil is unknown. However, it is estimated that at a minimum, $40-65 \%$ of the dose is absorbed and peak plasma concentrations $\left(\mathrm{C}_{\max }\right)$ are reached at 2-3 hours [4]. The presence of food in the gastrointestinal tract may delay the absorption of the drug by $0.5-1$ hour but the total amount absorbed is not affected [5].

Modafinil has been approved by the FDA for use in patients with narcolepsy, shift-work sleep disorder (SWSD) and obstructive sleep apnoea (OSA) with residual excessive daytime sleepiness (EDS) despite optimal treatment with continuous positive airway pressure (CPAP). It improves excessive sleepiness and illness severity in all three disorders [6]. Modafinil is partially metabolized by the cytochrome P450 isoenzymes. In addition, it also has enzyme-inducing and inhibiting activity. Use with other drugs that inhibit, induce, or act as a substrate to these isoenzymes such as oral contraceptives and antiepileptics may result in changes in plasma concentration of modafinil and/or the other drug $[7,8]$.

Studies to establish bioequivalence (BE) between two products are important for certain changes before approval regulatory submissions. In BE studies, an applicant compares the systemic exposure profile of a test drug product to that of a reference drug product. For two orally administered drug products to be bioequivalent, the active drug ingredient or active moiety in the test product must exhibit equivalent rate and extent of absorption to that of the reference drug product. Product quality BE frequently relays on pharmacokinetics measures such as AUC and $C_{\text {max }}$ that are reflective of systemic exposure [9]. For modified-release products, the following studies are recommended: (1) a single-dose, nonreplicate, fasting study comparing the highest strength of the test and reference listed drug product and (2) a food effect, nonreplicate study comparing the highest strength of the test and reference product. For immediate release products, a single-dose, fasting study is recommended. In addition, in vivo BE studies are to be

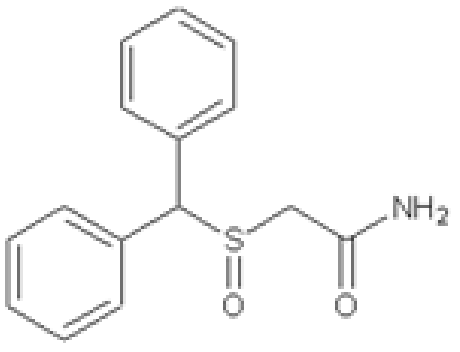

Figure 1: Modafinil structural formula

*Corresponding author: Omari D, STD, The specialized Pharmaceutical Research Co., Amman, Jordan, Tel: 96279 5013327; E-mail: derar@omariyapharma.com

Received December 05, 2014; Accepted January 18, 2014; Published January 22, 2015

Citation: Sallam A, Salem II, AlJohari D, Shawer M, Alaasal BA, et al. (2015) Bioequivalence of Two Oral Formulations of Modafinil Tablets in Healthy Male Subjects under Fed and Fasting Conditions. J Bioequiv Availab 7: 063-067. doi:10.4172/jbb.1000216

Copyright: $\odot 2015$ Sallam A, et al. This is an open-access article distributed under the terms of the Creative Commons Attribution License, which permits unrestricted use, distribution, and reproduction in any medium, provided the original author and source are credited. 
accompanied by in vitro dissolution profiles on all strengths of each product [9]. Modafinil was marketed in the US by Cephalon Inc. under the brand name of Provigil' in 2001[10]. Modafinil Tablets, $100 \mathrm{mg}$ and $200 \mathrm{mg}$, had US sales of $\$ 1.2$ billion for the 12 months ending March 31, 2012, according to IMS Health [11]. Many generic brands have been approved lately for the US market [12]. The Hikma modafinil tablets was guaranteed a US patent number $8,173,169$ on dry granulation process using modafinil particles have a size distribution such that at least about $65 \%$ of the modafinil particles have a diameter greater than 220 microns [13]

Literature search showed no studies concerning modafinil bioequivalence, therefore the aim of this study was to determine bioequivalence of two tablet formulations: Hikma modafinil 200 $\mathrm{mg}$ tablet relative to the originator Provigil $200 \mathrm{mg}$ tablets after oral administration to healthy subjects under both fed and fasting conditions.

\section{Subjects and Methods}

\section{Subjects}

Healthy Jordanian male subjects gave written informed consent to participate in the two studies before screening. The studies were approved by the Institutional Review Board at IPRC and were performed in accordance with the Good Clinical Practice guideline and the Declaration of Helsinki. Subjects included in the two studies were within $15 \%$ of their ideal body weight and were judged to be healthy based on medical history, physical examination, complete blood count, serum chemistry, and lack of hepatic, renal, respiratory, cardiac, or gastrointestinal conditions. In both studies, no subjects took any medication, including over-the-counter drugs, for 7 days before the study. Subjects were negative for HIV, hepatitis B and C viruses, and the presence of illegal drugs. The subjects did not participate in any other clinical study, donate blood, or require hospitalization within 3 months before initiation of both studies. The subjects were under continuous medical observation by the investigators and attending physicians during both studies. Follow-up medical testing (vital signs, physical examination, ECG, biochemistry, hematology, and urinalysis) was conducted on all subjects at discharge from both studies, and the subjects were questioned about adverse events by the investigators Table 1 shows number and demographic data for the subjects enrolled in the two studies, fast and fed. In either study, 28 subjects were enrolled and completed the crossover.

\section{Study drugs}

Two products of modafinil $200 \mathrm{mg}$ tablets were studied. The test product, modafinil $200 \mathrm{mg}$ tablets (Batch no. DJ002) manufactured by Hikma- Pharma, Jordan; while the reference product was Cephalon, Inc., Provigil", $200 \mathrm{mg}$ modafinil per tablet (Batch no. TEX115). The same batches were used for fasting and fed studies.

\section{Methods}

The method was designed as open-label, randomized two-way

\begin{tabular}{|c|c|c|}
\hline Characteristics & Fed study & Fast study \\
\hline No enrolled & 28 & 28 \\
\hline No completed the study & 28 & 28 \\
\hline Mean age $(\mathrm{yr}) \pm$ SD & $27 \pm 5.52$ & $26 \pm 4.61$ \\
\hline Mean body wt $(\mathrm{Kg}) \pm$ SD & $73 \pm 9.53$ & $71 \pm 10.35$ \\
\hline Mean height $(\mathrm{cm}) \pm$ SD & $173 \pm 6.16$ & $172 \pm 5.36$ \\
\hline
\end{tabular}

Table 1: Subjects enrolled in the study: their number and demographic characteristics. crossover study with a 7-day washout period for each study. Subjects were admitted the night before the study's drug administration, supervised for at least 10 hours overnight fasting, and confined until collecting the 24 hour sample. On study day 1 , each subject received a single dose of the assigned modafinil formulation in the randomized plan, along with $240 \mathrm{ml}$ of water.

No consumption of alcohol was permitted for the subjects 48 hours prior to the study's drug administration until donating the last sample of each respective period. Moreover, no consumption of beverages or foodstuffs containing methyl-xanthines, e.g. caffeine (coffee, tea, cola, cocoa, chocolate, etc.) was permitted for the subjects 24 hours prior to the study's drugs administration until the end of confinement period. In addition, the consumption of any beverages or foodstuffs containing grapefruit was prohibited one week before first study's drugs administration and throughout the entire study.

Food and fluid-intake were identical in both study periods, standardized in composition and amount and served approximately at the same time. The subjects were not allowed to consume any additional beverages or foodstuffs other than those provided throughout the period of confinement. Subjects consumed high fat breakfast half hour before drug administration during both periods of the study under fed conditions.

\section{Sample handling and sampling schedule}

Blood samples were collected in heparinized tubes before dosing (0.00 hour) and at the following times after the dose: $0.50,1.00,1.50$, $1.75,2.00,2.25,2.50,2.75,3.00,3.25,3.50,3.75,4.00,5.00,6.00$, $8.00,12.00,16.00,24.00,48.00$ and 72.00 hours. The samples were centrifuged and the resulting plasma was immediately stored at a nominal temperature of $-20^{\circ} \mathrm{C}$.

Plasma samples were analyzed by using a fast, simple and sensitive liquid chromatography-ultraviolet method developed and validated at IPRC bioanalytical labs. Following a simple extraction procedure, the analytes were separated on $\mathrm{C}_{18}$ column. Methanol, acetic acid \& dionized water were used to prepare the mobile phase. Detection was carried out on a Waters 2487 dual $\lambda$ UV detector. The validation was performed adhering to international guidance. The method was tested for linearity over the working range of $(0.10-110.00) \mu \mathrm{g} / \mathrm{ml}$. Validation parameters were: specificity, selectivity, linearity, sensitivity, accuracy, precision, intra and inter day accuracy and precision, recovery, short and long term stability, as well, matrix dilution integrity, freeze and thaw, autosampler, dry extract and stock solutions stability.

\section{Pharmacokinetics calculations}

Pharmacokinetic parameters of modafinil were estimated using standard non-compartmental methods. The maximal plasma concentration $\left(\mathrm{C}_{\max }\right)$ and the time to the peak plasma concentration $\left(\mathrm{T}_{\max }\right)$ of modafinil were taken directly from the measured data. The area under the plasma concentration-time curve $\left(\mathrm{AUC}_{0-\mathrm{f}}\right)$ was calculated from measured data points from time of administration to time of last quantifiable concentration $\left(\mathrm{C}_{\text {last }}\right)$ by the linear trapezoidal rule. The area under the plasma concentration-time curve extrapolated to infinity $\left(\mathrm{AUC}_{0-\infty}\right)$ was calculated according to the following formula:

$\mathrm{AUC}_{0-\infty}=\mathrm{AUC}_{0-\mathrm{t}}+\mathrm{C}_{\text {last }} /\left[\ln _{2} / \mathrm{t}_{1 / 2 \mathrm{e}}\right]$ where $\mathrm{C}_{\text {last }}$ is the last quantifiable concentration. The ratio $\mathrm{AUC}_{0-\mathrm{t}} / \mathrm{AUC}_{0-\infty}$ as a percent was determined as an indicator for the adequacy of sampling time. The elimination half-life $\left(t_{1 / 2}\right)$ was calculated as: $t_{1 / 2 e}=\operatorname{Ln}(2) /(-b)$, where $b$ was obtained as the slope of the linear regression of the Ln-transformed plasma 
concentrations versus time in the terminal period of the plasma curve. The pharmacokinetic calculations were using Kinetica ${ }^{\mathrm{TM}} 2000$ software [14].

\section{Statistical analyses}

Statistical analysis was performed by using the Kinetica using Kinetica $^{\mathrm{TM}} 2000$ software. The extent of absorption is determined by $\mathrm{AUC}_{0-\mathrm{t}}$ and $\mathrm{AUC}_{0-\infty}$. The rate of absorption is determined by $\mathrm{C}_{\max }$. For the parametric analysis of bioequivalence for Ln-transformed data, the acceptance boundaries were set at $80.00-125.00 \%$ for both $\mathrm{AUC}_{0-\mathrm{t}}$, and $\mathrm{C}_{\max }$. A multiplicative model with respect to the untransformed bioequivalence parameters was selected.

A logarithmic transformation of the original data was used. Under the assumption of a logarithmic normal distribution, a parametric approach recommended by [15] based on the inclusion of the shortest $90 \%$ confidence interval in the bioequivalence range was adopted. Analysis of variance (ANOVA) was tested for sequence; period, subject (sequence) and treatment effects were used. ANOVA was performed on $\mathrm{AUC}_{0-\mathrm{t}}, \mathrm{AUC}_{0-\infty}, \mathrm{C}_{\max }, \mathrm{t}_{\max }, \mathrm{t}_{1 / 2 \mathrm{e}}, \mathrm{K}_{\mathrm{e}}, \mathrm{Ln} \mathrm{AUC}_{0-\mathrm{t}}, \mathrm{Ln} \mathrm{AUC}_{0-\infty}$ and $\mathrm{Ln}$ $\mathrm{C}_{\max }$.

Descriptive statistics, including the means, standard deviations and coefficient of variation, were reported for the plasma concentrations. For the pharmacokinetic parameters, geometric means, arithmetic means, standard deviations and coefficient of variation were reported. Analyses of variance (ANOVA) were performed on the untransformed pharmacokinetic parameters listed above, namely, $\mathrm{AUC}_{0 \mathrm{t}}, \mathrm{AUC}_{0-\infty}, \mathrm{C}_{\text {max }}$ ' $t_{\max }, t_{1 / 2 e}, K_{e}, \operatorname{Ln} A_{U C} C_{0-t}, \operatorname{Ln} A_{U C}$ and $\operatorname{Ln} C_{\max }$ with the exception of the ratio of $\mathrm{AUC}_{0-\mathrm{t}}$ to $\mathrm{AUC}_{0-\infty}$. Additionally, logarithmically transformed (natural logarithm) data was used for analysis of $\mathrm{AUC}_{0-\infty}, \mathrm{AUC}_{0-\mathrm{t}}$ and $\mathrm{C}_{\max }$. The analysis of variance model included sequence; subjects nested within sequence, period and drug formulation as factors, employing $5 \%$ level of significance. The significance of the sequence effect was tested using the subjects nested within sequence, as the error term. Consistent with the two one-sided tests for bioequivalence [16] 90\% confidence intervals for the ratio of drug formulation means was calculated for the logarithmically transformed parameters $\mathrm{AUC}_{0-\mathrm{t}}, \mathrm{AUC}_{0-}$ and $\mathrm{C}_{\max }$.

\section{Results}

The described analytical method was proved selective and specific. Retention times were 6.1 and 8.8 min for modafinil and the internal standard, respectively (Figure 2). No interferences were observed. Concomitant drugs did not interfere with modafinil or internal standard analysis. The method was proved sensitive and accurate for the determination of modafinil in human plasma. Under the described conditions, the limit of quantitation for modafinil was $0.10 \mu \mathrm{g} / \mathrm{ml}$ with $103.3 \%$ accuracy and $15.9 \% \mathrm{CV}$. The method was found linear within the range $0.10-10.00 \mu \mathrm{g} / \mathrm{ml}$, with accuracy ranging $95.0-105.0 \%$ and precision 1.7-8.5 \%. Correlations coefficients were better than 0.98 . Intraday accuracy of modafinil method ranged from 107.7 to $114.0 \%$, while precision ranged from 2.1 to $13.5 \%$. Interday accuracy ranged from 97.0 to $114.0 \%$, while the interday precision ranged from 2.5 to $9.2 \%$. Mean recovery was proved to be $71.9 \%$ with $7.2 \% \mathrm{CV}$. Modafinil was found to be stable for 130 days at $-20^{\circ} \mathrm{C}(96.6 \%$ with $1.6 \% \mathrm{CV})$.

Drug plasma levels were designated as surrogate parameters to indicate clinical activity. Primary pharmacokinetic parameters were set to be $\mathrm{C}_{\max }$ and $\mathrm{AUC}_{0-\mathrm{t}}$ was also considered to be the bioequivalence determinants. Finally, $\mathrm{K}_{\mathrm{e}}, \mathrm{AUC}_{0-\infty}, \mathrm{t}_{\max }, \mathrm{AUC}_{0-\mathrm{t}} / \mathrm{AUC}_{0-\infty}$ and $\mathrm{t}_{1 / 2 \mathrm{e}}$ were set as the secondary pharmacokinetic parameters. The detailed results for fed and fasting studies are shown in Tables 2-5, respectively. Bioequivalence could be demonstrated for modafinil within the prescribed $90 \%$ confidence interval of $80.00-125.00 \%$ for $\mathrm{AUC}_{0-\mathrm{t}}$ and $\mathrm{C}_{\max }$ with respect to the parametric method on log-transformed data. The results are shown in Figures 2-4 for fed and fasting studies, respectively.

\section{Discussion}

Assessment of bioequivalence of generic product to reference product is required to exclude any clinically important differences in the rate or extent at which the active entity of the drugs becomes available at the site of action. Two drug products are considered to be bioequivalent if they are pharmaceutically equivalent and their bioavailability is so similar that they are unlikely to produce clinically relevant differences in regard to safety and efficacy [9]. Food has been shown to alter the bioavailability of some drugs which can have negative impact on the interpretation of bioequivalence results between test and reference products [14]. Food can alter bioavailability by various means, including delay gastric emptying, stimulate bile flow, change gastrointestinal (GI) $\mathrm{pH}$, increase splanchnic blood flow, change luminal metabolism of a drug substance and physically or chemically interact with a dosage form or a drug substance [9].

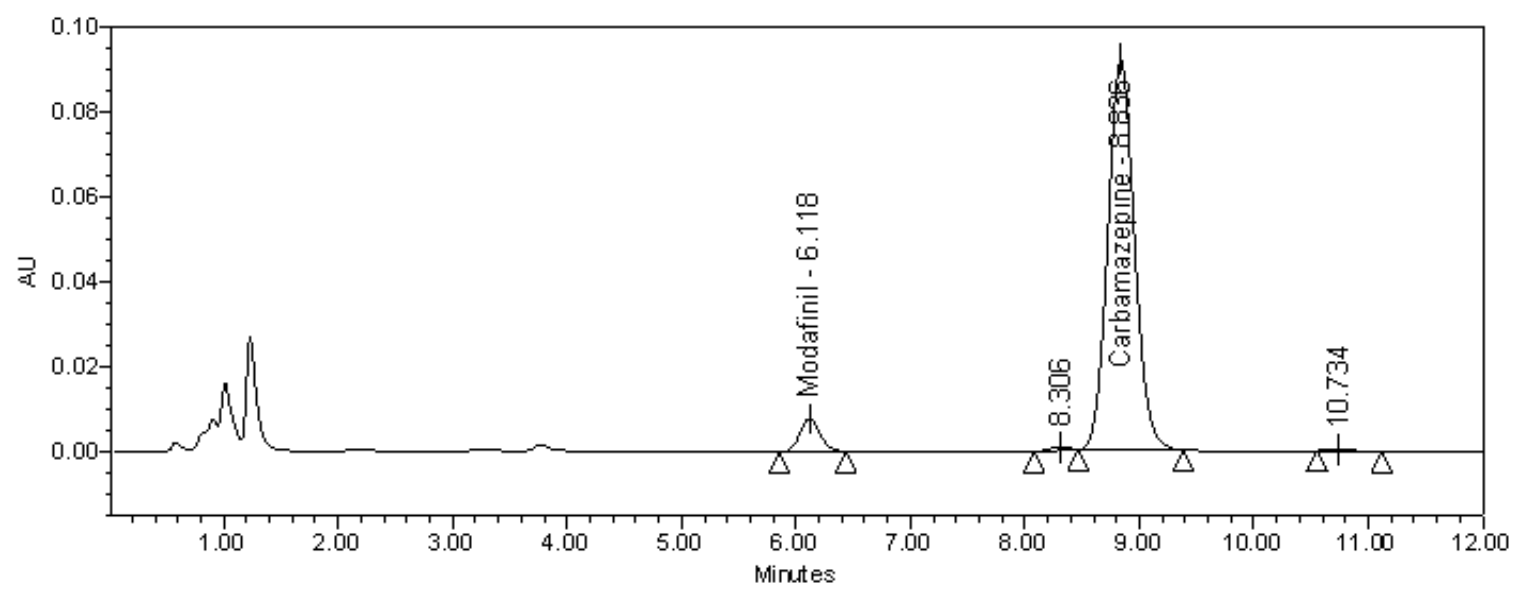

Figure 2: HPLC-UV chromatogram showing human plasma sample containing $0.30 \mu \mathrm{g} / \mathrm{ml}$ modafinil and $3.00 \mu \mathrm{g} / \mathrm{ml}$ internal standard. 
Citation: Sallam A, Salem II, AlJohari D, Shawer M, Alaasal BA, et al. (2015) Bioequivalence of Two Oral Formulations of Modafinil Tablets in Healthy Male Subjects under Fed and Fasting Conditions. J Bioequiv Availab 7: 063-067. doi:10.4172/jbb.1000216

\begin{tabular}{|c|c|c|c|}
\hline \multirow{2}{*}{ Parameter } & \multicolumn{3}{|c|}{$\mathbf{9 0 \%}$ Confidence intervals of parametric means } \\
\cline { 2 - 4 } & Point estimate \% & Lower Limit \% & Upper Limit \% \\
\hline $\boldsymbol{C}_{\boldsymbol{m a x}}$ & 99.86 & 94.49 & 105.53 \\
\hline AUC $_{\boldsymbol{0}-\boldsymbol{t}}$ & 107.60 & 103.53 & 111.83 \\
\hline $\boldsymbol{A} \boldsymbol{U} \boldsymbol{C}_{\boldsymbol{0}-\boldsymbol{\infty}}$ & 105.47 & 102.47 & 108.56 \\
\hline
\end{tabular}

Table 2: Bioequivalence confidence intervals of modafinil for fed study (Hikma modafinil $200 \mathrm{mg}$ tablet as a test product versus Provigil ${ }^{\circledR} 200 \mathrm{mg}$ tablet as reference product)

\begin{tabular}{|c|c|c|}
\hline \multirow{2}{*}{ Pharmacokinetic Parameter } & \multicolumn{2}{|c|}{ Treatment (Mean \pm SD) } \\
\hline & Test Product & Reference Product \\
\hline$C_{\max }(\mu g / m l)$ & $3.82 \pm 0.83$ & $3.79 \pm 0.66$ \\
\hline$A U C_{0-t}(\mu g \cdot h / m I)$ & $46.74+11.76$ & $43.10 \pm 9.88$ \\
\hline$A \cup C_{0-\infty}(\mu g \cdot h / m l)$ & $50.21 \pm 11.16$ & $47.42 \pm 9.78$ \\
\hline$t_{\max }(h)$ & $2.84 \pm 1.54$ & $2.65 \pm 1.40$ \\
\hline$t_{1 / 2 \mathrm{e}}(h)$ & $12.34 \pm 3.21$ & $12.01 \pm 3.24$ \\
\hline$A \cup C_{0-t} / A \cup C_{0-\infty}(\%)$ & $92.46 \pm 4.61$ & $90.76 \pm 6.56$ \\
\hline$K_{e}(1 / h)$ & $0.0612 \pm 0.02$ & $0.0621+0.02$ \\
\hline
\end{tabular}

Table 3: Pharmacokinetics parameters of modafinil for fed study (Hikma modafinil $200 \mathrm{mg}$ tablets as a test product versus Provigil ${ }^{\circledR} 200 \mathrm{mg}$ tablet as reference product).

\begin{tabular}{|c|c|c|c|}
\hline \multirow{2}{*}{$\begin{array}{c}\text { Pharmacokinetic } \\
\text { Parameter }\end{array}$} & \multicolumn{3}{|c|}{ 90\% Confidence intervals of parametric means } \\
\cline { 2 - 4 } & Point estimate \% & Lower Limit \% & Upper Limit \% \\
\hline $\boldsymbol{C}_{\boldsymbol{m a x}}$ & 96.59 & 92.03 & 101.38 \\
\hline AUC $_{\boldsymbol{0}-\boldsymbol{t}}$ & 102.29 & 97.51 & 107.29 \\
\hline $\boldsymbol{A U C}_{\boldsymbol{0}-\boldsymbol{\infty}}$ & 101.98 & 98.64 & 105.44 \\
\hline
\end{tabular}

Table 4: Bioequivalence confidence intervals of modafinil for fasting study (Hikma modafinil $200 \mathrm{mg}$ tablets as a test product versus Provigi ${ }^{\circledR} 200 \mathrm{mg}$ tablets as a reference product)

The results of this bioequivalence study showed the equivalence of the two studied products in terms of the rate of absorption as indicated by $\mathrm{C}_{\max }$ and in terms of the extent of absorption as indicated by $\mathrm{AUC}_{0-\mathrm{t}}$ and $\mathrm{AUC}_{0}$. The parametric $90 \%$ confidence intervals of the mean values for the Test/Reference ratio were in each case well within the bioequivalence acceptable boundaries of 80.00-125.00\% for the pharmacokinetic parameters $\mathrm{AUC}_{0-\mathrm{t}}, \mathrm{AUC}_{0-\infty}$ and $\mathrm{C}_{\max }$. Although

\begin{tabular}{|c|c|c|}
\hline \multirow{2}{*}{ Pharmacokinetic Parameter } & \multicolumn{2}{|c|}{ Treatment (Mean \pm SD) } \\
\hline & Test Product & Reference Product \\
\hline$C_{\max }(\mu g / m l)$ & $4.26 \pm 0.62$ & $4.42 \pm 0.74$ \\
\hline$A U C_{0-t}(\mu g \cdot h / m l)$ & $53.57 \pm 17.47$ & $51.88 \pm 15.08$ \\
\hline$A U C_{0-\infty}(\mu g \cdot h / m l)$ & $57.74 \pm 18.31$ & $56.00 \pm 14.96$ \\
\hline$t_{\max }(h)$ & $2.21 \pm 0.62$ & $1.75 \pm 0.58$ \\
\hline$t_{1 / 2 \mathrm{e}}(h)$ & $12.99 \pm 4.06$ & $12.66 \pm 3.46$ \\
\hline$A U C_{0-t} / A U C_{0-\infty}(\%)$ & $92.39 \pm 3.67$ & $92.16 \pm 4.67$ \\
\hline$K_{e}(1 / h)$ & $0.0582 \pm 0.02$ & $0.0586 \pm 0.02$ \\
\hline
\end{tabular}

Table 5: Pharmacokinetics parameters of modafinil for fasting study (Hikma modafinil $200 \mathrm{mg}$ tablets as a test product versus Provigil ${ }^{\circledR} 200 \mathrm{mg}$ tablets as a reference product).

the Provigil leaflet claimed that no effect of food on the absorption of the drug [10]; yet our results showed significant food effect where the $\mathrm{AUC}_{0-\mathrm{t}}$ and $\mathrm{AUC}_{0-\infty}$ of the reference product were lower in the fed study compared with fasting $\left(\mathrm{p}=0.0295\right.$ and 0.0396 for the $\mathrm{AUC}_{0-\mathrm{t}}$ and $\mathrm{AUC}_{0-\infty}$, respectively). Oppositely, the test product did not show significant food effect ( $\mathrm{p}=0.1667$ and 0.1284 for the $\mathrm{AUC}_{0-\mathrm{t}}$ and $\mathrm{AUC}_{0-\infty}$, respectively).

ANOVA analysis on the logarithmically transformed data, $\mathrm{AUC}_{0-\mathrm{t}}$, $\mathrm{AUC}_{0-\infty}$ and $\mathrm{C}_{\max }$ and untransformed data for $\mathrm{AUC}_{0-\mathrm{t}}, \mathrm{AUC}_{0-\infty}, \mathrm{C}_{\max }$, $t_{\max }, K_{e}$ and $t_{1 / 2 e}$ showed that sequence effect, product or period effect for all these parameters did not significantly influence the outcome of the study. The mean plasma curves of both products are almost superimposable suggesting that not only $\mathrm{C}_{\max }$ and AUC but also the time course of plasma levels over the whole sampling period are identical.

Since plasma levels are a meaningful surrogate for pharmacodynamic action and adverse events, this demonstrates that an equivalent therapeutic activity and tolerance is to be expected from modafinil (Hikma Pharmaceuticals-PLC, Jordan) Test product as compared to Provigil', the Reference product.

\section{Conclusion}

It is concluded that the bioequivalence parameters (AUC and Cmax) obtained after the oral administration under fed and fasting conditions of modafinil test product vs. Provigil ${ }^{\circ}$ were statistically

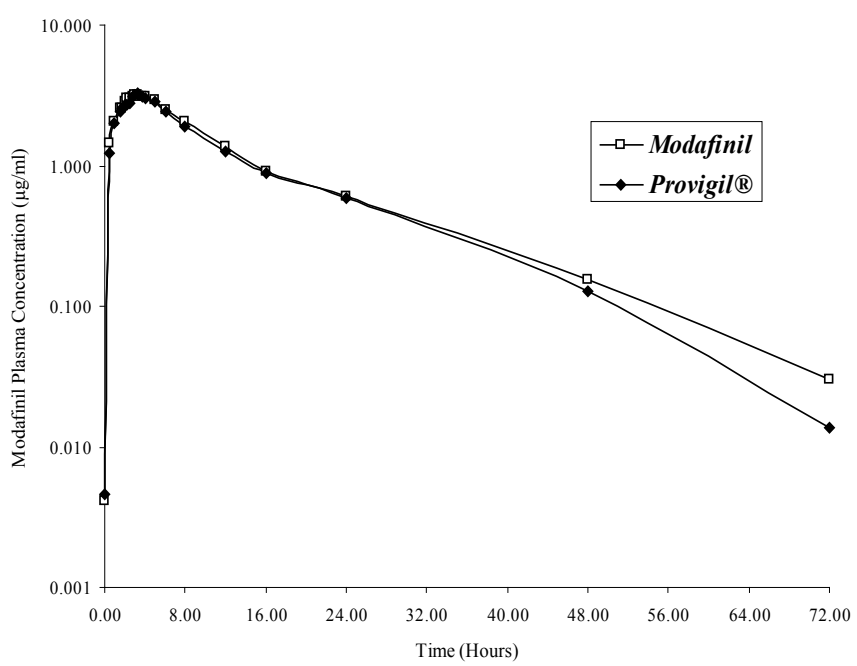

Figure 3: Modafinil mean plasma concentration after an oral dose administration of $200 \mathrm{mg}$ modafinil from Hikma modafinil 200 mg per tablet (test product) and Provigil ${ }^{\circledR}$ $200 \mathrm{mg}$ per tablet (reference product) to 28 healthy subjects under fed conditions (Plot A: plasma concentration vs. time, Plot B: log transformed plasma (conc. vs. time). 

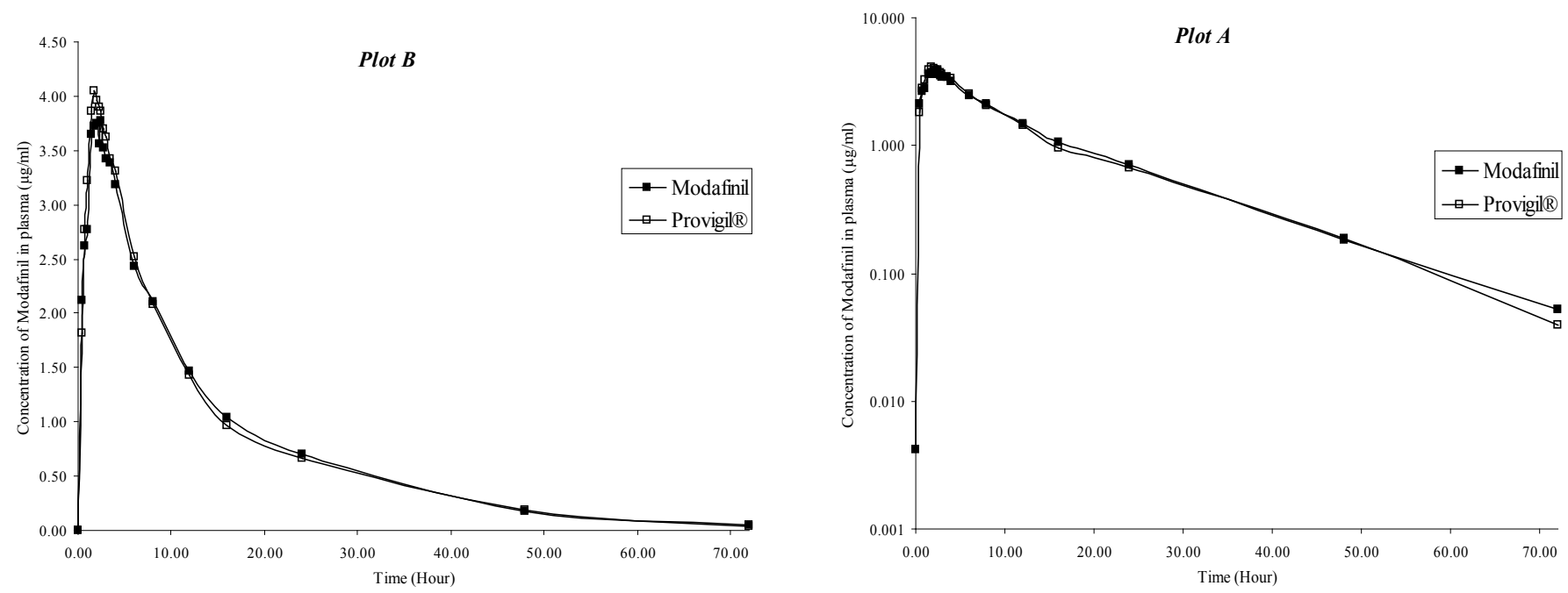

Figure 4: Modafinil mean plasma concentration after an oral dose administration of 200 mg modafinil from Hikma modafinil 200 mg per tablet (test product) and Provigi ${ }^{\circledR} 200 \mathrm{mg}$ per tablet (reference product) to 28 healthy subjects under fasting conditions (Plot A: plasma concentration vs. time, Plot B: log transformed plasma (conc. vs. time).

similar. The confidence intervals for $\mathrm{C}_{\max }, \mathrm{AUC}_{0-\mathrm{t}}$ and $\mathrm{AUC}_{0-\infty}$ are fully laid within the acceptable range of bioequivalence criteria $(80-125 \%)$, thus the two formulations are considered to be bioequivalent.

\section{References}

1. Robertson P Jr, Hellriegel ET (2003) Clinical pharmacokinetic profile of modafinil. Clin Pharmacokinet 42: 123-137.

2. Wong YN, King SP, Simcoe D, Gorman S, Laughton W (1999) Open-label, single-dose pharmacokinetic study of modafinil tablets: influence of age and gender in normal subjects. J Clin Pharmacol 39: 281-288.

3. Wong YN, King SP, Laughton WB, McCormick GC, Grebow PE (1998) Singledose pharmacokinetics of modafinil and methylphenidate given alone or in combination in healthy male volunteers. J Clin Pharmacol 38: 276-282.

4. Wong YN, Simcoe D, Hartman LN, Laughton WB, King SP, et al. (1999) A doubleblind, placebo-controlled, ascending-dose evaluation of the pharmacokinetics and tolerability of modafinil tablets in healthy male volunteers. J Clin Pharmacol 39: $30-40$.

5. Moachon G, Kanmacher I, Clenet M, Matinier D (1996) Pharmacokinetic profile of modafinil. Drugs Today 32: 327-337.

6. Raminder Kumar (2008) Approved and investigational uses of modafinil: An evidence-based review. Drugs 68: 1803-1839.
7. Sweetman SC (2009) Martindale, The complete drug reference, $36^{\text {th }}$ (Edn).

8. Scammell TE, Estabrooke IV, McCarthy MT, Chemelli RM, Yanagisawa M, et al. (2000) Hypothalamic arousal regions are activated during modafinil-induced wakefulness. J Neurosci 20: 8620-8628.

9. Rockville MD (2002) Food and Drug Administration. Guidance for industry: Bioavailability and bioequivalence studies for orally administered drug products - General considerations.

10. http://en.wikipedia.org/wiki/Modafinil

11. http://investor.mylan.com/releasedetail.cfm?Release

12. http://www.accessdata.fda.gov/scripts/cder/ob/default.cfm

13. Shawer M, Sallam A, Jawhari, D (2012) Formulation and process for the preparation of modafinil United States Patent No 8,173,169 B2.

14. Kinetica ${ }^{\mathrm{TM}} 2000$, V 4.2, User Manual, Innaphase 1999, France.

15. Schuirmann DJ (1987) A comparison of the two one- sided tests procedure and the power for assessing the equivalence of average bioavailability. $J$ Pharmacokinet Biopharm 15: 657-680.

16. Steinijans V, Diletti E (1983) Statistical analysis of bioavailability studies: Parametric and nonparametric confidence intervals. Eur J Clin Pharmacol 24 127-136. 